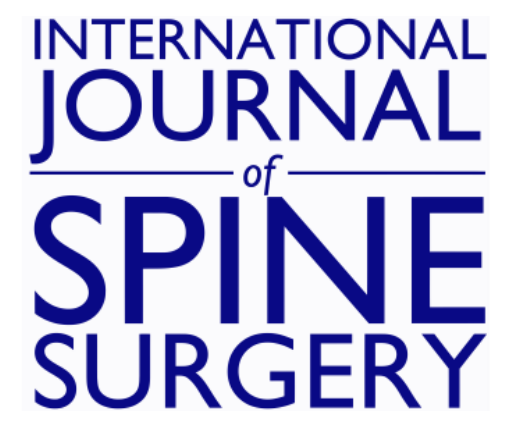

\title{
Long Term Societal Costs of Anterior Discectomy and Fusion (ACDF) versus Cervical Disc Arthroplasty (CDA) for Treatment of Cervical Radiculopathy
}

Ahmer Ghori, Joseph F. Konopka, Heeren Makanji, Thomas D. Cha and Christopher M. Bono

Int J Spine Surg 2016, 10 ()

doi: https://doi.org/10.14444/3001

http://ijssurgery.com/content/10/1

This information is current as of April 26, 2023.

Email Alerts Receive free email-alerts when new articles cite this article. Sign up at:

http://ijssurgery.com/alerts

The International Journal of Spind Surgerbhttp://ijssurgery.com/ by guest on April 26, 2 2397 Waterbury Circle, Suite 1,

Aurora, IL 60504, Phone: +1-630-375-1432

(C) 2016 ISASS. All Rights Reserved. 


\section{Long Term Societal Costs of Anterior Discectomy and Fusion (ACDF) versus Cervical Disc Arthroplasty (CDA) for Treatment of Cervical Radiculopathy}

Ahmer Ghori, MD, ${ }^{1}$ Joseph F. Konopka, MD, MSc, ${ }^{1}$ Heeren Makanji, MD,1 Thomas D. Cha, MD, MBA, ${ }^{2}$ Christopher M. Bono, MD 3

${ }^{1}$ Harvard Combined Orthopaedic Residency Program, Boston, MA, ${ }^{2}$ Massachusetts General Hospital, Boston, MA, ${ }^{3}$ Brigham and Women's Hospital, Boston, $M A$

\section{Abstract}

Background

Current literature suggests that anterior cervical discectomy and fusion (ACDF) and cervical disc arthroplasty (CDA) have comparable clinical outcomes for the treatment of cervical radiculopathy. Given similar outcomes, an understanding of differences in long-term societal costs can help guide resource utilization. The purpose of this study was to compare the relative long-term societal costs of anterior cervical discectomy and fusion (ACDF) to cervical disc arthroplasty (CDA) for the treatment of single level cervical disc disease by considering upfront surgical costs, lost productivity, and risk of subsequent revision surgery.

Methods

We completed an economic and decision analysis using a Markov model to evaluate the long-term societal costs of $\mathrm{ACDF}$ and $\mathrm{CDA}$ in a theoretical cohort of 45-65 year old patients with single level cervical disc disease who have failed nonoperative treatment.

Results

The long-term societal costs for a 45-year old patient undergoing ACDF are $\$ 31,178$ while long-term costs for CDA are $\$ 24,119$. Long-term costs for CDA remain less expensive throughout the modeled age range of 45 to 65 years old. Sensitivity analysis demonstrated that CDA remains less expensive than ACDF as long as annual reoperation rate remains below $10.5 \%$ annually.

\section{Conclusions}

Based on current data, CDA has lower long-term societal costs than ACDF for patients 45-65 years old by a substantial margin. Given reported reoperation rates of $2.5 \%$ for CDA, it is the preferred treatment for cervical radiculopathy from an economic perspective.

KEYWORDS: CERVICAL RADICULOPATHY, CERVICAL DISC ARTHROPLASTY (CDA), ANTERIOR CERVICAL DISCECTOMY AND FUSION (ACDF) VOLUME 10 ARTICLE 1 DOI: 10.14444/3001

\section{Introduction}

Anterior cervical discectomy and fusion (ACDF) is a widely accepted treatment option for the management of cervical radiculopathy that has failed conservative treatment. ${ }^{1-3}$ The procedure was first introduced in 1958 and is considered to be safe and costeffective..$^{4-5}$ However, one concern with ACDF is that it alters normal cervical spine biomechanics to place additional stress at adjacent levels, leading to adjacent level degeneration. ${ }^{6-7}$ The incidence of symptomatic adjacent segment disease has been estimated to be as high as $26 \%$ within 10 -years of the index proce- dure.$^{8}$ Of note, the perspective that ACDF predisposes patients to adjacent-segment disease is somewhat controversial, as adjacent level disease may simply be due to natural progression of degenerative disc disease. For instance, pre-existing degenerative changes at the adjacent levels was found to be the greatest risk factor for the development of adjacentlevel disease in the same study. ${ }^{8}$

Cervical disc arthroplasty (CDA) was developed to retain natural biomechanics in an effort to minimize adjacent level disease. Cadaveric data demonstrates significantly increased adjacent level intra-disc pres- 
sures in ACDF, yet no difference in intra-disc pressure and kinematics in adjacent levels after CDA. ${ }^{6-7}$ Furthermore, several recent randomized trials have shown comparable clinical outcomes between CDA and $\mathrm{ACDF}$ and some data even suggests superior performance of CDA. ${ }^{9-15}$ For instance, 5-year data from the ProDisc-C prosthesis (Synthes Spine Company, L.P., West Chester, PA) FDA trial demonstrated that CDA had a reoperation rate of $2.9 \%$ compared with a reoperation rate of $14.5 \%$ for ACDF. ${ }^{14}$ Threeyear data on the Bryan cervical disc prosthesis (Medtronic Sofamor Danek, Memphis, TN, USA) demonstrated improved functional outcome scores in CDA compared to ACDF patients in a relatively small randomized trial of 83 patients. Furthermore, a recent meta-analysis of six randomized controlled trials involving a total of 1,745 patients comparing ACDF and CDA found that CDA patients had a lower incidence of dysphasia and a lower reoperation rate related to adjacent segment degeneration..$^{10} \mathrm{On}$ the other hand, another meta-analysis by Gao et al. of 27 randomized controlled studies demonstrated shorter operative times and blood loss for ACDF compared to CDA. ${ }^{16}$

Two prior studies have examined the costeffectiveness of ACDF compared to CDA. Warren et al. compared outcomes at two years for a small group of 28 patients, finding both ACDF and CDA to be cost-effective at a $\$ 50,000$ willingness-to-pay threshold, although the authors found a higher increase in quality-adjusted life years (QALYs) in the ACDF group. ${ }^{17}$ This study was limited by the small sample size and relatively short follow-up. Qureshi et al. created a decision tree analysis comparing $\mathrm{ACDF}$ and $\mathrm{CDA}$, finding CDA to be a cost-effective alternative to $\mathrm{ACDF}$ as long as prosthesis survival approaches 11 years. ${ }^{18}$ However, this study was limited by the lack of aggregate data to generate health state utility factors for ACDF compared to CDA, and only included hospital charges and surgeon fees in its cost analysis.

Because the clinical outcomes of ACDF and CDA appear to be comparable based on the current literature, the goal of this study is to model the long-term societal costs of each surgical strategy. Given that recent analysis suggests similar short-term healthrelated quality of life (HRQoL) for each procedure, the less expensive treatment strategy would be preferred from society's perspective. ${ }^{19-21}$

\section{Materials and Methods}

\section{Analytic Overview}

We developed a Markov state-transition computer simulation of alternative surgical treatment options for patients with symptomatic single level cervical disc disease who have failed conservative therapy. The model was created using TreeAge Pro software (TreeAge Pro 2013; TreeAge software, Williamstown, Massachusetts). The model was used to examine the long-term resource utilization of two treatment strategies for symptomatic single level cervical disc disease: ACDF or CDA. Analysis was performed from the societal perspective. All costs were measured in 2012 US dollars and discounted at an annual rate of $3 \%$. Our analysis conformed to the guidelines of the US Panel on Cost-Effectiveness in Health and Medicine. ${ }^{20-21}$

\section{Model Structure}

Figure 1 depicts the structure of the Markov model. Patients enter the model at the time of surgery, when they face a risk of perioperative mortality. After surgery, patients enter a "well post-operative" status. Each year, the patients in this health state are at risk for requiring a revision procedure, which may be either an index level or adjacent level revision ACDF procedure. During the revision procedure, patients again face a risk of perioperative mortality. After revision surgery, surviving patients enter another "well post-operative" state. We assume that only a single revision procedure will occur for any patient in the model. The model runs until all patients have died.

\section{Patient Population}

The average age of onset of symptomatic cervical disc disease is reported to be 47.6 years in males, and 48.2 years in females. ${ }^{22}$ We therefore analyze a theoretical cohort of patients aged 45 to 65 years old with symptomatic single level cervical disc disease who have failed non-operative management.

\section{Transition Probabilities}

Table 1 summarizes the key transition probabilities used in the model. We estimated the annual probabil- 
ity that a patient undergoing ACDF or CDA would require a revision surgery at the index or adjacent level based on results reported in seven prospective, randomized studies that compared ACDF to CDA. ${ }^{9,11-15,23}$ We determined the mean annual probability of reoperation weighted by study sample size using a total of 1554 patients across all studies. This yielded an annual failure rate of $5.8 \%$ for $\mathrm{ACDF}$ (of which $65 \%$ represented reoperation at the index level and $35 \%$ at an adjacent level), and 2.5\% for CDA (of which $63 \%$ represented reoperation at the index level and $37 \%$ at an adjacent level). We estimated perioperative mortality to be $0.07 \%$ from the same data set. Annual other cause mortality rates were determined from US Life Tables. ${ }^{24}$

\section{Direct Costs}

Table 1 summarizes cost data used in the model. We included costs associated with primary ACDF, CDA, and revision $\mathrm{ACDF}$ for index-level or adjacent-level disease. For each procedure, we estimated preoperative costs, peri-operative costs, and postoperative costs using Medicare data. All costs were

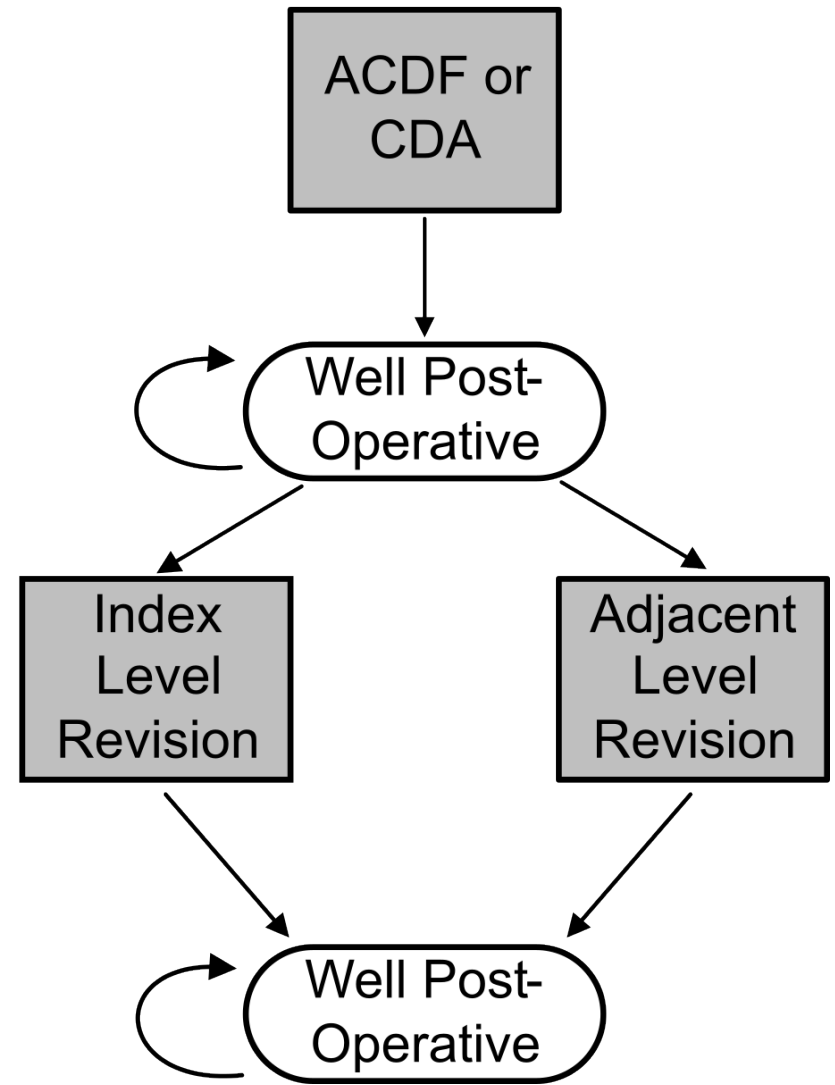

Fig. 1. Structure of the Markov model. Only one possible revision surgery per patient is assumed. converted to 2012 U.S. dollars using the Medical component of the Consumer Price Index. ${ }^{25}$

Pre-operative costs included the cost of physician visits as well as complete pre-operative images, including cervical spine plain films, non-contrast cervical spine CT, and non-contrast cervical spine MRI. These costs were estimated using the Physician Fee Schedule for $2012 .{ }^{26} \mathrm{We}$ also estimated the cost of pre-operative labs, which included a basic metabolic panel, complete blood count, partial thromboplastin time, and international normalized ratio (INR) using the Clinical Diagnostic Laboratory Fee Schedule. ${ }^{27}$ Given a similar pre-operative workup for both ACDF and CDA, our estimated pre-operative costs are $\$ 1,118$ for both procedures.

Peri-operative costs included anesthesia and surgeon

\begin{tabular}{|c|c|c|c|c|c|}
\hline \multicolumn{2}{|l|}{ Variable } & \multicolumn{2}{|l|}{ ACDF } & \multicolumn{2}{|l|}{ CDA } \\
\hline \multirow{4}{*}{$\begin{array}{l}\text { Transition } \\
\text { Probabilities }\end{array}$} & $\begin{array}{l}\text { Annual Probability } \\
\text { of Disease } \\
\text { Recurrence }\end{array}$ & $5.8 \%$ & $9,11,13-15,23$ & $2.5 \%$ & $9,11,13-15,23$ \\
\hline & $\begin{array}{l}\text { Recurrence at Index } \\
\text { Level }\end{array}$ & $65 \%$ & $9,11,13-15,23$ & $63 \%$ & $9,11,13-15,23$ \\
\hline & $\begin{array}{l}\text { Recurrence at } \\
\text { Adjacent Level }\end{array}$ & $35 \%$ & $9,11,13-15,23$ & $37 \%$ & $9,11,13-15,23$ \\
\hline & Perioperative Death & $0.07 \%$ & $9,11,13-15,23$ & $0.07 \%$ & $9,11,13-15,23$ \\
\hline \multirow{7}{*}{$\begin{array}{l}\text { Direct Costs } \\
\text { (2012 USD) }\end{array}$} & $\begin{array}{l}\text { Pre-operative } \\
\text { Workup* }\end{array}$ & $\$ 1,188$ & 26,27 & $\$ 1,188$ & 26,27 \\
\hline & Anesthesia Fee $\dagger$ & $\$ 516$ & 12,28 & $\$ 516$ & 12,28 \\
\hline & Surgeon Fee & $\$ 2,110$ & 26 & $\$ 1,675$ & 26 \\
\hline & $\begin{array}{l}\text { Surgery and Acute } \\
\text { Care } \S\end{array}$ & $\$ 9,735$ & 29 & $\$ 8,668$ & 29 \\
\hline & $\begin{array}{l}\text { Rehab or home } \\
\text { health care¥ }\end{array}$ & $\$ 182$ & $31-33$ & $\$ 36$ & $31-33$ \\
\hline & Medications & $\$ 112$ & 30 & $\$ 112$ & 30 \\
\hline & Annual Monitoring $\diamond$ & $\$ 251$ & 26 & $\$ 251$ & 26 \\
\hline $\begin{array}{l}\text { Indirect } \\
\text { Costs (2012 } \\
\text { USD) }\end{array}$ & Lost productivity** & $\$ 6,066$ & $9,11,13,25$ & $\$ 4,621$ & $9,11,13,25$ \\
\hline \multicolumn{6}{|c|}{$\begin{array}{l}\text { *Physician visits, plain films, CT, MRI, and pre-operative labs; †Based on } \\
106 \text { minutes of intra-operative time; } § \text { Surgery technical costs and inpatient } \\
\text { stay; ¥Based on the percentage of patients that require post-op skilled } \\
\text { nursing facility or home health care; } \diamond \text { Cost of physician visits and imaging } \\
\text { for two annual visits; ** Lost productivity due to recovery from surgery. } \\
\text { Abbreviations: ACDF, anterior cervical discectomy and fusion; CDA, } \\
\text { cervical disc arthroplasty; USD, United States Dollars; CT, computed } \\
\text { tomography; MRI, magnetic resonance imaging. }\end{array}$} \\
\hline
\end{tabular}


fees, as well as the technical costs of surgery and acute inpatient recovery. Anesthesia fees were estimated using the Anesthesia Fee Schedule as well as estimated length of procedures from Murrey et al. ${ }^{12,28}$ Given the similar operative times of 103 minutes for CDA and 106 minutes for ACDF, we estimated similar anesthesia fees for both procedures. Surgeon fees were estimated using the Physician Fee schedule. ${ }^{26}$ Technical costs of surgery as well as acute postoperative recovery costs were estimated using Medicare Diagnosis-Related Group (DRG) data. ${ }^{29}$ Our total peri-operative costs estimates are $\$ 12,361$ for ACDF and \$10,859 for CDA, which are similar to other recent estimates. ${ }^{18}$ While reimbursement for CDA is slightly lower, the implant cost for CDA is certainly higher. This difference is not reflected in the societal cost but rather constitutes a hospital cost that is absorbed by the institution.

Post-operative costs included the cost of medications, post-operative rehabilitation, and postoperative monitoring. We determined the costs of post-operative medications by apply average medication prices to a typical post-operative pain medication regimen. ${ }^{30}$ To determine post-operative rehabilitation resource use, we first estimated the utilization rates by using Healthcare Cost and Utilization Project (HCUP) data. ${ }^{31}$ These data demonstrated that a slightly higher percentage of ACDF patients in the 45-64 year age range require either home health care or discharge to a post-acute (10\% versus $2 \%$ ). We assumed such patients would require one week of either home health care or a stay at a skilled nursing facility, and estimated cost per day based on published data. ${ }^{32-33}$ To determine the costs of post-operative monitoring, we estimated the costs of two annual post-operative physician visits with plain films at each visit, based on expert opinion. Our estimates for total post-operative costs are $\$ 545$ for ACDF and \$399 for CDA.

\section{Indirect Costs}

The indirect cost from each procedure consisted of the lost productivity sustained by patients as they recover from surgery. We determined the average days spend in post-operative recovery by calculating the mean weighted by study sample size of several randomized trials that compared recovery times of
ACDF to CDA. ${ }^{9,11,13}$ From this value, we estimated lost productivity by multiplying the fraction of the year spent recovering by the US GDP per capita in $2012 .{ }^{25}$ Our indirect cost estimates are $\$ 6,066$ for $\mathrm{ACDF}$ and $\$ 4,621$ for CDA; this difference was due to a shorter estimated recover time after CDA. Of note, we assumed patients would retire at age 65 and we therefore did not include this cost if the patient underwent a revision procedure after this age.

\section{Sensitivity Analysis}

We conducted sensitivity analysis to determine how uncertainty in the underlying data parameters affects our conclusions. We utilized both one-way and twoway sensitivity analyses for all key model parameters to determine how the relative long-term costs of each procedure change based on variations in the underlying input data.

\section{Results}

\section{Base Case}

Table 2 describes the results of the base case. For a 45-year old patient, the long-term societal costs were $\$ 31,780$ for ACDF and $\$ 24,119$ for CDA. CDA was less expensive for all patients in the 45 to 65 year old age range, although the cost-differential narrows from $\$ 7,661$ when a patient is 45 years old at the time of index surgery to $\$ 6,008$ when a patient is 65 years old at the time of index surgery.

\section{Sensitivity Analysis}

The value of several key parameters influenced which procedure had the highest long-term costs. The most influential variables were the annual reoperation rate of CDA, the peri-operative costs of

\begin{tabular}{|c|c|c|c|}
\hline Patient Age & ACDF & CDA & Difference \\
\hline 45 & $\$ 31,780$ & $\$ 24,119$ & $\$ 7,661$ \\
\hline 50 & $\$ 30,968$ & $\$ 23,437$ & $\$ 7,531$ \\
\hline 55 & $\$ 29,846$ & $\$ 22,610$ & $\$ 7,236$ \\
\hline 60 & $\$ 28,238$ & $\$ 21,588$ & $\$ 6,650$ \\
\hline 65 & $\$ 26,630$ & $\$ 20,621$ & $\$ 6,008$ \\
\hline
\end{tabular}


$\mathrm{CDA}$, and the peri-operative costs of ACDF. The average annual reoperation rate for CDA needs to remain below 10.5\% for CDA to remain less expensive than ACDF (Figure 2). Two-way sensitivity analysis demonstrates that this value increases up to an annual reoperation rate of $13.1 \%$ as patient age at the time of index surgery increases from 45 to 65 years old. Two-way sensitivity analysis also demonstrates that the CDA remains less expensive than ACDF unless peri-operative costs for CDA are significantly higher than those in the base case or ACDF peri-operative costs are significantly lower than estimated in the base case (Figure 3). Of note, other variables in the model, including age at the index procedure, postoperative costs, and indirect costs associated with recover, did not alter the conclusion of the model when varied over a plausible range.

\section{Discussion}

Several recent studies have suggested that ACDF and CDA produce a comparable clinical outcome for the treatment of single level cervical disc disease. ${ }^{9-14,16}$ We therefore sought to determine which of these procedures has the greater long-term expense for society. Based on the best available current data, our study finds that the long-term costs of CDA are significantly lower than that of ACDF.

Furthermore, our sensitivity analysis demonstrates that this finding is robust: $\mathrm{CDA}$ is less expensive than ACDF over a plausible range of values for our model input parameters. For instance, CDA remains less

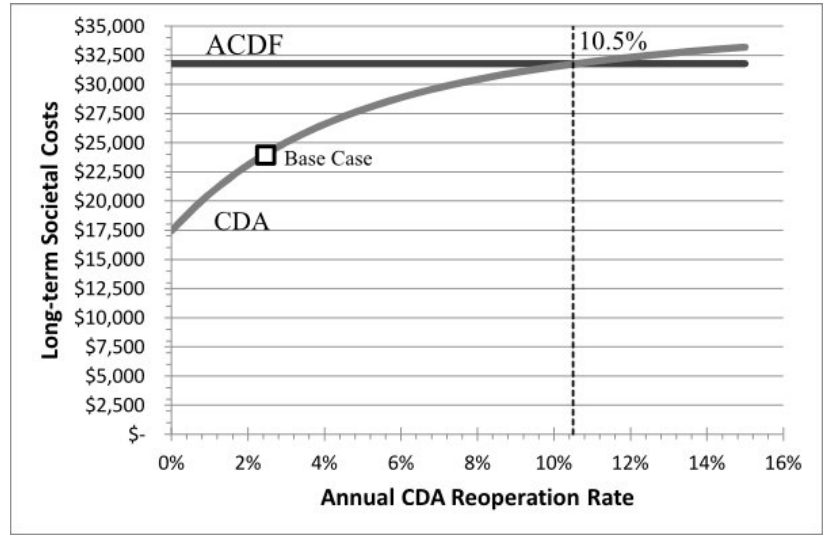

Fig. 2. Sensitivity analysis of long term costs of ACDF versus $C D A$ as influenced by the annual $C D A$ reoperation rate. The average annual reoperation rate for $\mathrm{CDA}$ needs to remain below $10.5 \%$ for $\mathrm{CDA}$ to remain less expensive than ACDF. expensive than $\mathrm{ACDF}$ as long as its average annual reoperation rate remains lower than $10.5 \%$, which is significantly higher than the $2.5 \%$ annual failure rate we estimated from recent literature describing 2-year and 5-year follow-up (Figure 2). This finding implies that 10 -year implant survival could be as low as $32 \%$ for CDA to remain less expensive. Although longterm CDA reoperation rates are not known, only a very large increase in reoperations rates in the midterm and long-term relative to the better delineated short-term reoperation rates would be necessary for $\mathrm{ACDF}$ to be less expensive. Additionally, CDA remains less expensive than ACDF unless perioperative costs for CDA are much higher or perioperative costs for ACDF are much lower than we estimated. Furthermore, our estimates for perioperative costs are similar to those found in recently published literature. $^{18}$

Several factors drive the finding that CDA has lower long-term costs than ACDF. First, CDA has lower peri-operative costs and slightly lower post-operative costs compared to ACDF. Second, the recovery period for CDA appears to be quicker based on recent data, which means less time that a patient loses productivity while recovering. ${ }^{911,13}$ Third, the lower reoperation rate for CDA patients means that these patients are less likely than ACDF patients to require a costly reoperation. ${ }^{9,11-15,23}$ Fourth, because of the lower reoperation rate for CDA, when CDA patients do require an operation, it tends to happen farther in the future and therefore the costs are more highly dis-

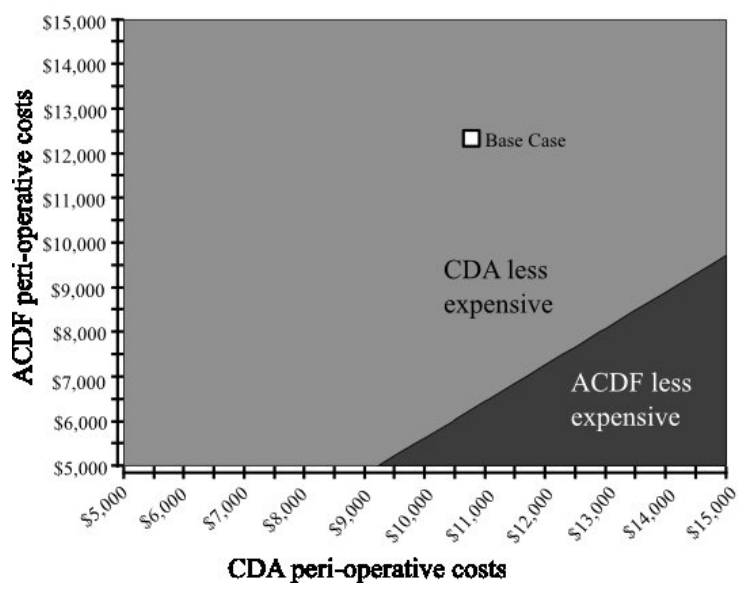

Fig. 3. Sensitivity analysis demonstrating that CDA remains less expensive than $A C D F$ unless peri-operative costs for $C D A$ are significantly higher or costs for ACDF are significantly lower than estimated in the base case. 
counted in present day terms.

Our study has several limitations. Many of the prospective studies comparing ACDF and CDA have been industry-sponsored, so there may be a bias against re-operating on CDA patients as well as other financial conflicts of interest. For instance, a nonindustry sponsored trial reported no difference in the rates of adjacent level disease between ACDF and CDA. ${ }^{34}$ Additionally, surgeons may be more likely to suspect adjacent level disease or pseudoarthrosis in symptomatic post-operative ACDF patients than in symptomatic post-operative CDA patients; this may lead to a higher likelihood of a surgeon offering revision surgery to ACDF patients with continued symptoms. However, given our sensitivity analysis findings, even if ACDF and CDA had equivalent reoperation rates, CDA would still be significantly less expensive. Another limitation of our study is that we applied Medicare cost data to a younger population of patients. Given the variations in medical costs across the country, we felt that Medicare data would be the most reliable source to approximate nationwide average costs. ${ }^{35}$ Our study is further limited by excluding utility analysis from our model. Although pre- and post- operative health-related quality of life (HRQoL) in ACDF patients has been studied, we are only aware of two studies that compare HRQoL of ACDF and CDA. ${ }^{17,19,36}$ Both studies found no statistically significant differences in HRQoL, but were limited by small sample sizes. Furthermore, since clinical outcomes are otherwise thought to be similar between ACDF and CDA, we felt that more highlypowered HRQoL data comparing ACDF and CDA was necessary to meaningfully include a utility analysis in our model. ${ }^{10}$ For instance, if outcomes of $\mathrm{ACDF}$ and CDA are indeed equivalent in HRQoL terms, the less expensive procedure would always be the preferred treatment strategy. ${ }^{17,19-20}$

Further shortcomings of this study are related to limitations of the source data as well as the Markov model. Individual patient data from one hospital or practice may provide a more interesting comparison but would not provide enough data to run the model nor have the same generalizability. While implant cost is incorporated into hospital reimbursement for DRGs, reoperation rates may be affected by the type of implant, biologics, and/or allografts used. Unfortunately, a large database with accurate reporting of these factors would be needed to allow such comparisons. Furthermore, hospital cost may be significantly dependent on the type of implant used and reimbursement rates may not capture this difference, although this discrepancy would not affect the cost to society. Source data was used for the age group 45-64, but it is possible that CDA patients were younger than $\mathrm{ACDF}$ patients within this range, thus affecting certain costs, such as the need for home health or a skilled nursing facility.

In conclusion, CDA has lower long-term costs from the societal perspective when compared to ACDF for the treatment of single-level disc disease. CDA is less expensive than $\mathrm{ACDF}$ over a plausible range of values for all our model input parameters, including average annual reoperation rate. Although the longterm reoperation rate of CDA has yet to be elucidated, we expect this analysis to remain valid unless a precipitous rise in reoperation rate is observed. Additional studies are required to determine both the long term reoperation rate of $\mathrm{CDA}$ as well as the comparative HRQoL between ACDF and CDA.

\section{References}

1. Bohlman HH, Emery SE, Goodfellow DB, Jones PK (1993). Robinson anterior cervical discectomy and arthrodesis for cervical radiculopathy. Longterm follow-up of one hundred and twenty-two patients. The Journal of bone and joint surgery. American volume 75(9):1298-1307.

2. Cloward RB (1958). The anterior approach for removal of ruptured cervical disks. Journal of Neurosurgery 15(6):602-617.

3. Yue WM, Brodner W, Highland TR (2005). Long-term results after anterior cervical discectomy and fusion with allograft and plating: a 5- to 11-year radiologic and clinical follow-up study. Spine (Phila Pa 1976) 30(19):2138-2144.

4. Smith GW, Robinson RA (1958). The treatment of certain cervical-spine disorders by anterior removal of the intervertebral disc and interbody fusion. The Journal of bone and joint surgery. American volume 40-A(3):607-624. 
5. Carreon LY, Anderson PA, Traynelis VC, Mummaneni PV, Glassman SD (2013). Cost-effectiveness of single-level anterior cervical discectomy and fusion five years after surgery. Spine 38(6):471-475. 6. Dmitriev AE, Cunningham BW, Hu N, Sell G, Vigna F, McAfee PC (2005). Adjacent level intradiscal pressure and segmental kinematics following a cervical total disc arthroplasty: an in vitro human cadaveric model. Spine 30(10):1165-1172.

7. Eck JC, Humphreys SC, Lim TH, et al (2002). Biomechanical study on the effect of cervical spine fusion on adjacent-level intradiscal pressure and segmental motion . Spine 27(22):2431-2434.

8. Hilibrand AS, Carlson GD, Palumbo MA, Jones PK, Bohlman HH (1999). Radiculopathy and myelopathy at segments adjacent to the site of a previous anterior cervical arthrodesis. The Journal of bone and joint surgery. American volume 81(4):519-528. 9. Cheng L, Nie L, Li M, Huo Y, Pan X (2011). Superiority of the $\operatorname{Bryan}((\mathrm{R}))$ disc prosthesis for cervical myelopathy: a randomized study with 3-year followup. Clinical orthopaedics and related research 469(12):3408-3414.

10. Jiang H, Zhu Z, Qiu Y, Qian B, Qiu X, Ji M (2012). Cervical disc arthroplasty versus fusion for single-level symptomatic cervical disc disease: a meta-analysis of randomized controlled trials.

Archives of orthopaedic and trauma surgery 132(2):141-151.

11. Mummaneni PV, Burkus JK, Haid RW, Traynelis VC, Zdeblick TA (2007). Clinical and radiographic analysis of cervical disc arthroplasty compared with allograft fusion: a randomized controlled clinical trial. Journal of Neurosurgery Spine 6(3):198-209.

12. Murrey D, Janssen M, Delamarter R, et al (2009). Results of the prospective, randomized, controlled multicenter Food and Drug Administration investigational device exemption study of the ProDisc-C total disc replacement versus anterior discectomy and fusion for the treatment of 1-level symptomatic cervical disc disease. The Spine Journal 9(4):275-286.

13. Heller JG, Sasso RC, Papadopoulos SM, et al (2009). Comparison of BRYAN cervical disc arthroplasty with anterior cervical decompression and fusion: clinical and radiographic results of a random- ized, controlled, clinical trial. Spine 34(2):101-107. 14. Delamarter RB, Zigler J (2013). Five-year reoperation rates, cervical total disc replacement versus fusion, results of a prospective randomized clinical trial. Spine 38(9):711-717.

15. Nabhan A, Steudel WI, Pape D, Ishak B (2007). Segmental kinematics and adjacent level degeneration following disc replacement versus fusion: RCT with three years of follow-up. Journal of long-term effects of medical implants 17(3):229-236.

16. Gao Y, Liu M, Li T, Huang F, Tang T, Xiang Z (2013). A meta-analysis comparing the results of cervical disc arthroplasty with anterior cervical discectomy and fusion (ACDF) for the treatment of symptomatic cervical disc disease. The Journal of bone and joint surgery. American volume 95(6):555-561.

17. Warren D, Hoelscher C, Ricart-Hoffiz P, Bendo J, Goldstein J (2011). Cost-utility analysis of anterior cervical discectomy and fusion versus cervical disc arthroplasty. Evidence-based spine-care journal 2(3):57-58.

18. Qureshi SA, McAnany S, Goz V, Koehler SM, Hecht AC (2013). Cost-effectiveness analysis: comparing single-level cervical disc replacement and single-level anterior cervical discectomy and fusion: clinical article. Journal of Neurosurgery Spine 19(5):546-554.

19. Qureshi S, Goz V, McAnany S, et al (2014). Health state utility of patients with single-level cervical degenerative disc disease: comparison of anterior cervical discectomy and fusion with cervical disc arthroplasty. Journal of Neurosurgery Spine 20(5):475-479.

20. Weinstein MC, Siegel JE, Gold MR, Kamlet MS, Russell LB (1996). Recommendations of the Panel on Cost-effectiveness in Health and Medicine. $J A M A$ : the journal of the American Medical Association 276(15):1253-1258.

21. Siegel JE, Weinstein MC, Russell LB, Gold MR (1996). Recommendations for reporting costeffectiveness analyses. Panel on Cost-Effectiveness in Health and Medicine. JAMA: the journal of the American Medical Association 276(16):1339-1341. 22. Radhakrishnan K, Litchy WJ, O'Fallon WM, Kurland LT (1994). Epidemiology of cervical radiculopathy. A population-based study from Rochester, Minnesota, 1976 through 1990. Brain : a journal of 
neurology 117 ( Pt 2):325-335.

23. Robertson JT, Papadopoulos SM, Traynelis VC (2005). Assessment of adjacent-segment disease in patients treated with cervical fusion or arthroplasty: a prospective 2-year study. Journal of Neurosurgery Spine 3(6):417-423.

24. Centers for Disease Control and Prevention. US Life Tables (2010) http://www.cdc.gov/.

25. Bureau of Labor Statistics US Department of Labor (2013).

26. Centers for Medicare \& Medicaid Services. Physician Fee Schedule (2012).

27. Centers for Medicare \& Medicaid Services. Clinical Laboratory Fee Schedule (2012).

28. Centers for Medicare \& Medicaid Services. 2012 Anesthesia Base Units by CPT Code (2012).

29. Centers for Medicare \& Medicaid Services. Diagnosis Related Group List, FY (2011).

30. Red Book Drug References: Thomson Reuters; (2012).

31. Agency for Healthcare Research and Quality. HCUP Databases. Healthcare Cost and Utilization Project (HCUP). Rockville, MD 2006-2009.

32. Buntin MDP, Escarce J; Hoverman C; Paddock S; Sood N (2005). Comparison of Medicare Spending and Outcomes for Beneficiaries with Lower Extremity Joint Replacements. RAND health working papers

33. Centers for Medicare \& Medicaid Services. Prospective payment systems and consolidated billing for skilled nursing facilities, FY (2012).

34. Nunley PD, Jawahar A, Kerr EJ, 3rd, et al (2012). Factors affecting the incidence of sympto- matic adjacent-level disease in cervical spine after total disc arthroplasty: 2- to 4-year follow-up of 3 prospective randomized trials. Spine 37(6):445-451. 35. Wennberg J, Gittelsohn. Small area variations in health care delivery (1973). Science 182(4117):1102-1108.

36. Klein GR, Vaccaro AR, Albert TJ (2000). Health outcome assessment before and after anterior cervical discectomy and fusion for radiculopathy: a prospective analysis. Spine 25(7):801-803.

\section{Disclosures}

All authors declare no relevant disclosures or conflicts of interest. Thomas Cha has received grant support from the Gordon and Betty Moore Foundation and the North American Spine Society; has received institutional fellowship support from $\mathrm{AO}$ Spine, and K2M, and has consulted for Bio2, GE Healthcare, and Nuvasive.

\section{Corresponding Author}

Heeren Makanji, Harvard Combined Orthopaedic Residency Program, 55 Fruit Street, White Building, 5th Floor, Boston, MA 02114. hmakan-

ji@partners.org.

Published 7 January 2016.

This manuscript is generously published free of charge by ISASS, the International Society for the Advancement of Spine Surgery. Copyright @ 2016 ISASS. To see more or order reprints or permissions, see http://ijssurgery.com. 